University of Nebraska - Lincoln

DigitalCommons@University of Nebraska - Lincoln

1985

\title{
The effects of prey depletion on the patch choice of foraging blue jays (Cyanocitta cristata)
}

\author{
Alan Kamil \\ University of Nebraska - Lincoln, akamil1@unl.edu \\ Sonja I. Yoerg \\ University of California, Berkeley
}

Follow this and additional works at: https://digitalcommons.unl.edu/bioscibehavior

Part of the Behavior and Ethology Commons

Kamil, Alan and Yoerg, Sonja I., "The effects of prey depletion on the patch choice of foraging blue jays (Cyanocitta cristata)" (1985). Papers in Behavior and Biological Sciences. 67.

https://digitalcommons.unl.edu/bioscibehavior/67

This Article is brought to you for free and open access by the Papers in the Biological Sciences at DigitalCommons@University of Nebraska - Lincoln. It has been accepted for inclusion in Papers in Behavior and Biological Sciences by an authorized administrator of DigitalCommons@University of Nebraska - Lincoln. 
Published in Animal Behaviour 33 (1985), pp. 1089-1095. Copyright @ 1985 by the Association for the Study of Animal Behaviour; published by Elsevier. Used by permission.

Submitted April 18, 1984; revised September 7, 1984.

\title{
The effects of prey depletion on the patch choice of foraging blue jays (Cyanocitta cristata)
}

\author{
Alan C. Kamil and Sonja I. Yoerg \\ Departments of Psychology and Zoology, University of Massachusetts, Amherst, MA 01003, USA \\ Present address for S. I. Yoerg - Department of Psychology, University of California, Berkeley, CA 96720, USA
}

\begin{abstract}
Blue jays (Cyanocitta cristata) were trained to hunt for non-cryptic moths presented in projected images. On each trial, the jays chose one of two patches to hunt in: (1) a uniform, "non-depleting" patch with constant prey density of 0.25 ; or (2) a "depleting" patch in which prey density changed during the foraging bout. In the depleting patch, the initial prey density was 0.50 , declining to zero in a single step part-way through each foraging bout (session). The patch choices of the jays were greatly affected by these conditions. The jays chose the depleting patch early in the session, and then switched to the uniform patch. They obtained nearly all of the prey available. Analysis of the events preceding switches between patches suggested that the jays used different rules to switch out of each of the two patches.
\end{abstract}

Many experiments have demonstrated that predators are quite sensitive to the distribution of prey within a foraging area (e.g. Smith \& Dawkins 1971; Krebs et al. 1974; Smith \& Sweatman 1974; Krebs et al. 1978; Kacelnik 1979). Where food is distributed in discrete, depletable patches, predators must first decide in which patch they will forage, and then must decide when to leave that patch and forage in another. The second decision is the concern of this experiment.

As a predator hunts in a patch, the probability of success in that patch usually decreases because of depletion. Persisting too long will result in a less than optimal rate of food intake, as will leaving the patch prematurely. Charnov (1976) provided a theoretical solution to this dilemma: a predator should abandon a given patch when the expected rate of capture in that patch (the "marginal capture rate") falls below the average capture rate in the entire foraging area. However, the overall rate of intake is a function of nonrandom patch residence times (McNair 1982), and the predator is unlikely to have direct knowledge of the marginal capture rate. Therefore, many authors have sought to identify some relatively simple within-patch parameters, such as number of prey found, time spent in patch or time since the last prey was found (givingup time), that may be used by a predator to determine when to give up (Gibb 1962; Charnov 1973; Krebs et al. 1974; Pyke et al. 1977).

Recently, Iwasa et al. (1981) demonstrated that the nature of the distribution of prey within a patch deter- mines which parameters will yield the most information about the expected value of that patch. For binomial distributions, the best indicator is the number of prey that have been taken within the patch, since the probability of success falls with each prey capture. For Poisson distributions, the best indicator is the time already spent in the patch.

In the present experiment, operant conditioning procedures were used to simulate the prey-depletion problem. Blue jays could choose to hunt in either of two patches on each trial. One patch contained a uniform, "non-depleting" distribution of prey, which maintained a constant marginal value throughout each session of the experiment. The other, "depleting" patch had a high marginal value at the beginning of each session, and then became depleted in a single step in a way designed to be analogous to either a Poisson or a binomial rule. The initial prey density in the depleting patch was higher than in the uniform patch, but decreased to zero during the session. This procedure was used to simplify the depletion problem and make the most efficient strategy unambiguous, so that we could determine if this general technique can be fruitfully applied to the study of the depletion problem.

We expected that after prolonged exposure to these conditions, the jays would begin each session in the depleting patch and remain there until the probability of finding a prey item was lower than in the non-depleting patch. The jays were then expected to 
choose the patch with the uniform distribution of prey for the remainder of the session. Following the arguments of Iwasa et al. (1981), it was also expected that the rule determining the switch from the depleting to the uniform patch would depend on whether the prey distribution in the depleting patch was Poisson or binomial.

\section{Method}

\section{Subjects}

The subjects were four blue jays (Cyanocitta cristata) taken from nests near Amherst, MA, at 10-14 days of age. The jays were of unknown sex, and had been hand-raised in the laboratory. All of the jays had received previous experience in the apparatus, including two pilot studies using depleting schedules. The jays were weighed daily and maintained at $75-80 \%$ of their free feeding weights by controlled daily feeding throughout the experiment.

\section{Apparatus}

The apparatus was a modified pigeon operant chamber $34.0 \times 30.0 \times 35.5 \mathrm{~cm}$. A food cup was located in the center of one wall, $1-3 \mathrm{~cm}$ above the floor. Reinforcers, half-pieces of Tenebrio larvae, were delivered to the cup by a Davis UF-100 universal feeder mounted on top of the chamber. The food cup was illuminated by a small $24-\mathrm{V}$ bulb whenever reinforcement was delivered. A $24-\mathrm{V}$ white house light was located above the magazine and was continuously lit during all sessions.

Two rectangular stimulus keys, $11.5 \mathrm{~cm}$ wide by $7.5 \mathrm{~cm}$ high, were located with their edges $0.5 \mathrm{~cm}$ from either side of the magazine and $12.5 \mathrm{~cm}$ above the floor. A programmable Kodak Carousel projector was mounted behind each stimulus key. A round key, 2.5 $\mathrm{cm}$ in diameter, was mounted below each rectangular key, $2.2 \mathrm{~cm}$ from the food cup. A small stimulus projector was mounted behind each round key. A round $1.2-\mathrm{cm}$ perch was placed parallel to the stimulus panel, $5 \mathrm{~cm}$ above the floor and $10 \mathrm{~cm}$ from the panel, so that the eye level of a jay on the perch was just below the center of the rectangular keys. Masking noise was produced by a ventilating fan and white noise played through a small speaker mounted behind the stimulus panel. All stimulus events and contingencies were controlled by a Lehigh Valley Electronics INTERACT computer system.
The slides projected onto the rectangular keys were prepared by photographing two artificial grey logs against a white background with a Nikkormat FTN camera with a $50 \mathrm{~mm}$ lens, at a subject-to-camera distance of $1.4 \mathrm{~m}$. Two types of slides were made. "Positive" slides included a Catocala relicta moth pinned on one of the logs, where it was quite conspicuous. Within the set, moths appeared equally often in each vertical third of each log. "Negative" slides had no moth, and just showed the two empty logs.

\section{General Procedure}

At the beginning of each session, the jay was placed in the chamber and the first trial began when a white horizontal line appeared on the left round key and a white vertical line appeared on the right round key. When the jay chose one of these keys by pecking at it, the round key not pecked became dark and inoperative for the rest of the trial, and all subsequent events for that trial occurred on the side initially chosen. The peck at the round key also initiated a 4-s delay simulating a "travel time" requirement, during which pecks had no effect. At the end of the travel time, the display on the round key changed to a yellow circle. A single peck at the yellow circle began the next stage of the trial, the search stage. The round key displayed a red circle, and a slide which might or might not contain a moth was projected onto the stimulus key above the round key.

The search stage ended when the jay made one of two responses: a peck at the red key or a peck at the slide projected on the rectangular key. A response on the red key ended the trial. Both keys became dark, and there was a 2-s interval during which the slide projector behind the stimulus key that had been illuminated advanced. (The other slide projector did not advance.) The next trial then began with the illumination of both round keys.

A response on the rectangular key resulted in the round key turning dark and becoming inoperative, but the rectangular key remained illuminated, and a 20-s interval, simulating a handling time requirement, began whether the slide contained a moth or not. During this interval, pecks had no effect, although the jays usually did peck at the slide. The first peck after the end of the handling time ended the trial and the rectangular key became dark. If there had been a moth in the slide, the feeder operated and a piece of mealworm was delivered into the food cup. Then there 
was a 2-s interval during which the slide projector advanced. If there had been no moth in the slide, no reinforcement was delivered, and the slide projector advanced immediately.

The basic concept behind this procedure was that the two rectangular keys represented two patches in which prey could be found. The sequence of events forced the birds to choose a patch at the beginning of each trial, then hunt in that patch, which contained either no prey or one prey item. To further emphasize the distinction between the two patches, a changeover delay was used. Whenever the jay began a trial by choosing the same side as it had chosen on the previous trial, the travel time was $4 \mathrm{~s}$. However, if the jay switched sides, choosing the side not chosen on the previous trial, a longer travel time requirement (8- or 16-s, see below) was used. As in a natural situation, then, it was more costly to travel between patches than to remain in the current patch.

Throughout the experiment, each session lasted for 36 trials, and there were two sessions per day, 67 days per week. The time between sessions was approximately $100 \mathrm{~min}$ for each bird. The experiment was conducted in three stages.

\section{Baseline}

All jays were first given 16 sessions of baseline training, with data collected during the last eight sessions. The distribution of slides containing moths (positives) was uniform on both keys, with $25 \%$ of the slides in each projector being positives. Slides were presented in a novel random order each session, with the restriction that no more than three consecutive positives or five consecutive negatives could occur. (This restriction was in force throughout the experiment). The travel time for changeover responses was $8 \mathrm{~s}$. Three of the four jays showed moderate-to-strong left preferences during the baseline stage. Therefore, the left side was designated the depleting patch in subsequent stages, since the experiment was focusing on the ability of the birds to learn to abandon the depleting patch part-way through each session.

\section{Depletion (short changeover delay)}

During this stage, the left set of keys represented the depleting patch, while the right set continued to contain the $25 \%$ uniform distribution. Two types of depleting sequences were used, binomial and Poisson. Since a discrete-trials procedure was employed, num- ber of trials was used as an indicator of the amount of time spent in a patch. In the binomial sequences, there were always six positives randomly distributed within the first 10-14 trials. In the Poisson sequences, there were always 5-7 positives randomly distributed within the first 12 trials. Once depletion had occurred, all remaining trials in the depleting sequences were negatives. New random sequences were generated for each session. The sequences were counterbalanced across 10 session blocks. For the Poisson distribution, there were 5,6 , or 7 positives within the first 12 trials of the session. (This was counterbalanced and randomized so that five- and seven-prey-item sessions occurred three times, and six-prey-item sessions four times, within each block of 10 sessions.) For the binomial distribution the six prey items occurred equally often within the first 10,11,12, 13, or 14 trials (each value was used twice within each block of 10 sessions, in random order). Thus the optimal point at which to switch differed for the binomial and Poisson cases. In the Poisson case, the best time to switch was after 12 trials. In the binomial, it was after six prey items had been found.

Two birds were randomly assigned to the Poisson condition (jays 20 and 34), the other two (jays 31 and $40)$ to the binomial. The original experimental design called for switching conditions after a stable pattern of responding had been obtained.

\section{Depletion (long changeover delay)}

During this stage, all conditions were identical to the previous stage except that the travel time for switching responses was increased from 8 to 16 s. Jays 20 and 40 became ill and died after completing 10 sessions with the longer changeover delay. The other two birds completed 20 sessions in this condition.

\section{Results}

In the data analyses, the experiment was divided into blocks, the last eight sessions of baseline (BL) and the 7-8 blocks of 10 sessions each (blocks 1-8). Repeatedmeasures analyses of variance were used for each dependent variable. BL was omitted from some of these analyses when the dependent variable could not be calculated meaningfully for BL conditions (there was no depleting patch during BL and the number of prey items available per session changed with the introduc- 


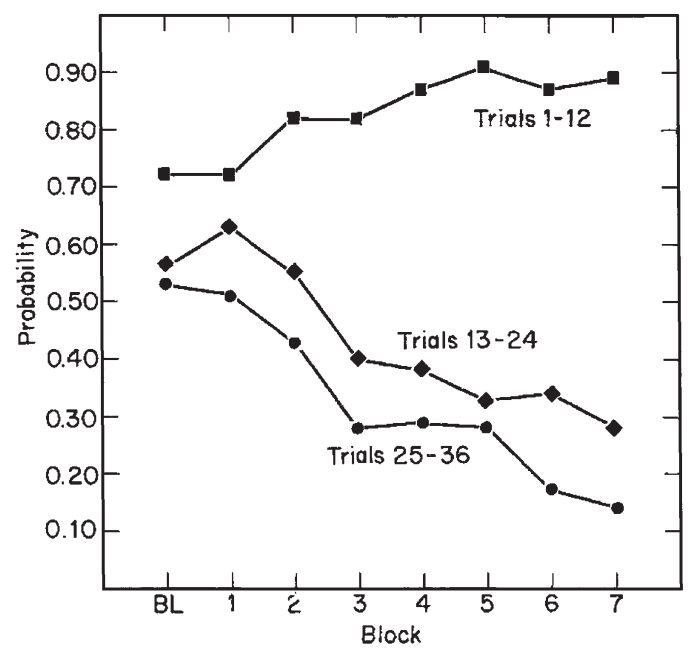

Figure 1. The mean probability of choosing the depleting patch during each block of the experiment, shown separately for each session third (separate averages for trials 1-12, 13-24 and 25-36).

tion of the depletion condition). The data from block 8, which included only two jays, were included only in analyses examining performance at the end of the experiment. The two birds in the binomial condition did not differ in any systematic way from the two birds in the Poisson condition (see Figures $2 \& 3$ below for individual data): therefore the four jays were treated as a single group.

The jays detected the moths very accurately throughout the experiment, pecking the projected image when a moth was present and pecking the red key when no moth was present. Errors were made on less than $1 \%$ of the trials. In the data analyses that follow, errors were treated as trials without prey, since no reinforcement was obtained.

During BL and block 1, the jays showed a distinct left preference, which was strongest during the first 12 trials (or first third) of the sessions. As the experiment proceeded, the jays learned about the distribution of prey within the patches. They chose the depleting patch more often during the first third of each session, but chose the depleting patch less often during the latter two-thirds of each session (Figure 1). When these data were subjected to a session-thirds by blocks analysis, the session-thirds by blocks interaction was significant, $F(14,42)=9.95, P<0-001$, showing that the learning reflected in this change in the shape of the within-session preference curve, was significant. At the end of the experiment, the patterns of choice were

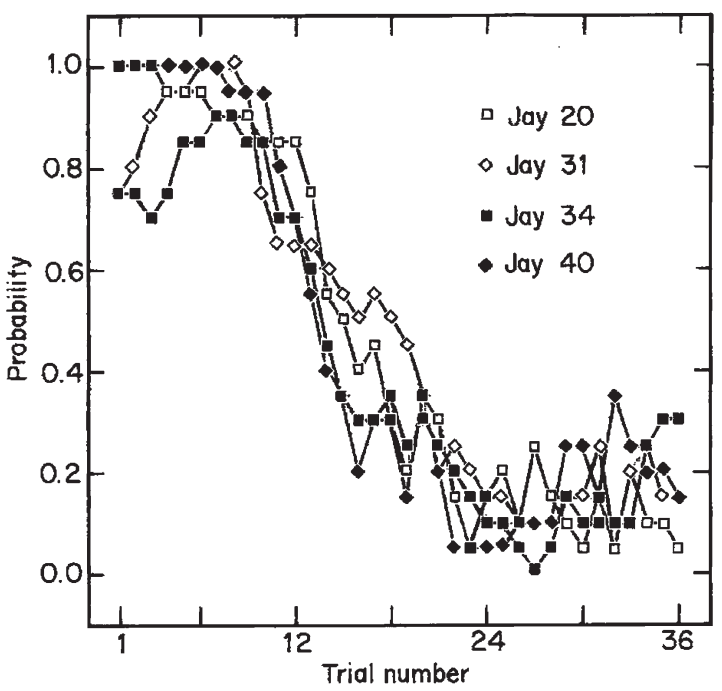

Figure 2. The mean probability of choosing the depleting patch for each jay on each trial of the session, averaged across the last two blocks of the experiment.

extremely consistent across jays, as shown in Figure 2.

A number of dependent variables changed significantly in the course of the experiment. These are summarized in Table 1 . There was a small, but significant and very consistent increase in the number of prey found per session from block 1 to block 7. (BL was omitted from this analysis since neither patch depleted during BL testing.)

The frequency and pattern of switching between patches also changed over the course of the experiment. A switch was defined as any choice of the patch not chosen on the previous trial. There was a significant decrease in the number of switches per session, and a significant increase in the number of trials before the first switch in the session (Table 1). The critical switch was defined as the first switch in a session after which $80 \%$ of the subsequent choices were made on the same side (similar to the $90 \%$ definition of Krebs et al. 1978; if no switch within the session met this definition, the value of the critical switch for that session was 36). Using this definition, the critical switch came significantly earlier in the sessions as the experiment proceeded (Table 1).

We also examined choice behavior after the last prey item had been found in the depleting patch. In general, the number of choices of the depleting patch after depletion was complete declined significantly across sessions as the experiment proceeded (Table 1). But the number of choices of the depleting patch 


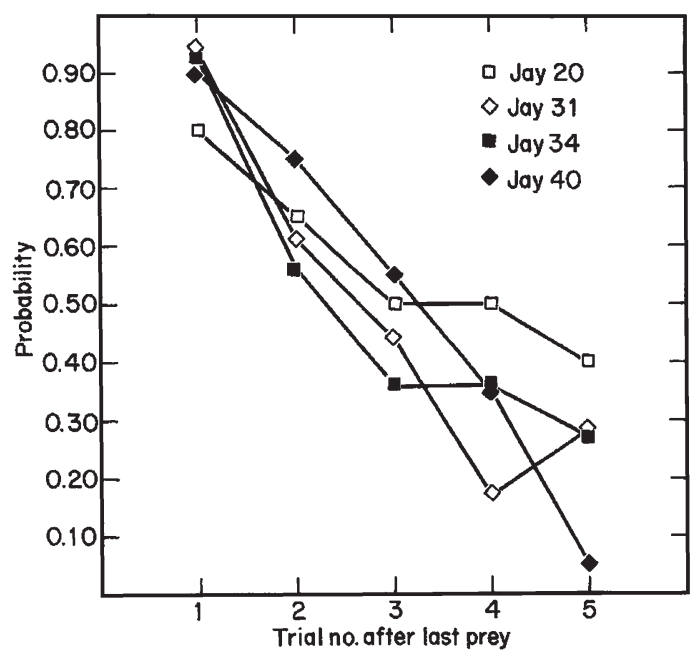

Figure 3. The mean probability of choosing the depleting patch for each jay shown as a function of the number of trials after the last prey item in the depleting patch had been found, averaged across the last two blocks of the experiment.

on the five trials immediately following the last prey item remained high, and did not change significantly from block 1 to block 7 (Table 1). As shown in Figure 3 , during the last two blocks of the experiment, the jays were abandoning the depleting patch during the first few trials following depletion. There were, however, no substantial or systematic differences between the Poisson and binomial birds in this tendency.

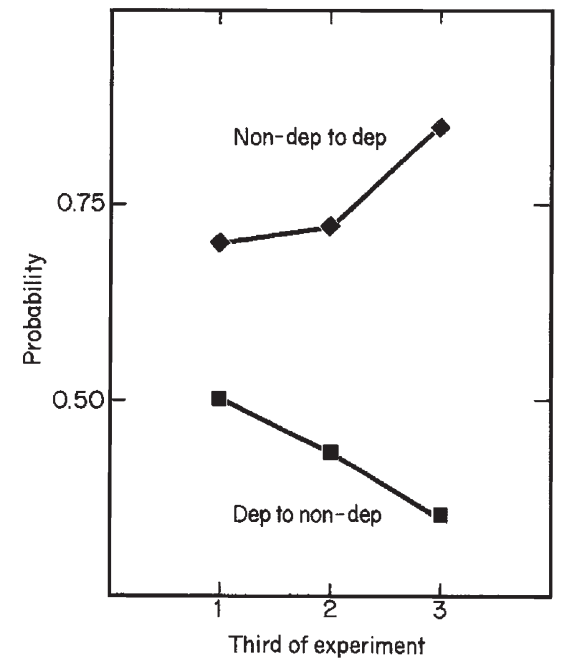

Figure 4. The mean probability that a switch between patches was preceded by a trial during which a moth was found, as a function of each third of the experiment, for switches from the non-depleting patch to the depleting patch (non-dep to dep) and vice versa (dep to non-dep).

We also analyzed the events preceding a switch in either direction. We included only the trials preceding the depletion of the left patch in this analysis, since after depletion was complete, all switches from the depleting patch would, perforce, have been preceded by a no-prey trial. As shown in Figure 4, switches from the depleting to the uniform patch tended to be preceded by a no-moth trial, while switches in the other

Table 1. Summary of changes in behavior over the course of the experiment

\begin{tabular}{|c|c|c|c|c|c|c|c|c|c|}
\hline \multirow[b]{2}{*}{ Measure } & \multirow[b]{2}{*}{ Baseline } & \multicolumn{7}{|c|}{ Block } & \multirow[b]{2}{*}{$F$-ratio } \\
\hline & & 1 & 2 & 3 & 4 & 5 & 6 & 7 & \\
\hline $\begin{array}{l}\text { Mean no. prey obtained per session } \\
\quad( \pm \text { SE })\end{array}$ & & $\begin{array}{c}9.32 \\
(0.65)\end{array}$ & $\begin{array}{l}9.85 \\
(0.58)\end{array}$ & $\begin{array}{c}10.55 \\
(0.38)\end{array}$ & $\begin{array}{c}10.42 \\
(0.24)\end{array}$ & $\begin{array}{c}10.72 \\
(0.22)\end{array}$ & $\begin{array}{l}10.75 \\
(0.12)\end{array}$ & $\begin{array}{c}10.72 \\
(0.18)\end{array}$ & $3.01^{*}$ \\
\hline $\begin{array}{l}\text { Mean no. switches per session } \\
\qquad( \pm \text { SE })\end{array}$ & $\begin{array}{c}8.15 \\
(1.34)\end{array}$ & $\begin{array}{c}6.72 \\
(1.14)\end{array}$ & $\begin{array}{c}6.38 \\
(1.33)\end{array}$ & $\begin{array}{c}6.58 \\
(1.70)\end{array}$ & $\begin{array}{c}5.90 \\
(1.29)\end{array}$ & $\begin{array}{c}5.72 \\
(1.05)\end{array}$ & $\begin{array}{c}5.08 \\
(1.12)\end{array}$ & $\begin{array}{l}4.10 \\
(0.96)\end{array}$ & $6.16^{* * *}$ \\
\hline $\begin{array}{l}\text { Mean no. trials before the first switch } \\
\quad( \pm \text { SE })\end{array}$ & $\begin{array}{c}5.80 \\
(1.01)\end{array}$ & $\begin{array}{c}6.32 \\
(1.62)\end{array}$ & $\begin{array}{c}9.42 \\
(1.84)\end{array}$ & $\begin{array}{c}7.83 \\
(1.91)\end{array}$ & $\begin{array}{c}10.12 \\
(1.32)\end{array}$ & $\begin{array}{l}11.15 \\
(1.42)\end{array}$ & $\begin{array}{l}12.10 \\
(2.13)\end{array}$ & $\begin{array}{l}11.98 \\
(0.78)\end{array}$ & $4.42^{* *}$ \\
\hline $\begin{array}{l}\text { Mean no. trials before the critical switch } \\
\qquad( \pm \text { SE })\end{array}$ & $\begin{array}{l}31.45 \\
(3.09)\end{array}$ & $\begin{array}{l}29.05 \\
(3.76)\end{array}$ & $\begin{array}{l}28.60 \\
(2.94)\end{array}$ & $\begin{array}{l}24.72 \\
(2.25)\end{array}$ & $\begin{array}{l}24.55 \\
(2.70)\end{array}$ & $\begin{array}{l}22.88 \\
(2.75)\end{array}$ & $\begin{array}{l}18.15 \\
(0.95)\end{array}$ & $\begin{array}{l}16.58 \\
(1.00)\end{array}$ & $6.29^{* * *}$ \\
\hline $\begin{array}{l}\text { Mean probability of choosing depleting patch } \\
\text { on all trials following depletion }( \pm \text { SE })\end{array}$ & & $\begin{array}{c}0.55 \\
(0.08)\end{array}$ & $\begin{array}{c}0.46 \\
(0.09)\end{array}$ & $\begin{array}{c}0.33 \\
(0.07)\end{array}$ & $\begin{array}{c}0.35 \\
(0.04)\end{array}$ & $\begin{array}{c}0.31 \\
(0.04)\end{array}$ & $\begin{array}{c}0.26 \\
(0.01)\end{array}$ & $\begin{array}{c}0.21 \\
(0.04)\end{array}$ & $6.10^{* *}$ \\
\hline $\begin{array}{l}\text { Mean probability of choosing depleting patch } \\
\text { on the } 5 \text { trials following depletion }( \pm \mathrm{SE})\end{array}$ & & $\begin{array}{c}0.66 \\
(0.05)\end{array}$ & $\begin{array}{c}0.59 \\
(0.10)\end{array}$ & $\begin{array}{c}0.46 \\
(0.03)\end{array}$ & $\begin{array}{c}0.62 \\
(0.06)\end{array}$ & $\begin{array}{c}0.54 \\
(0.07)\end{array}$ & $\begin{array}{c}0.54 \\
(0.08)\end{array}$ & $\begin{array}{c}0.50 \\
(0.05)\end{array}$ & $1.26 \mathrm{NS}$ \\
\hline
\end{tabular}

${ }^{*} P<0.05 ;{ }^{* *} P<0.01 ; * * * P<0.001 ; d f=7,21$ when BL included; $d f=6,18$ when BL not included. 
direction tended to be preceded by a slide containing a moth. This difference is actually greater than it appears on the surface. If switches occurred at random in each direction, then switches out of the nondepleting patch would have been preceded by prey $25 \%$ of the time; switches out of the depleting patch before depletion occurred would have been preceded by prey $50 \%$ of the time. Analysis of variance of these data, with direction of switch and third of the experiment as factors, revealed that the difference between the two switching directions was significant, $F(1,3)=$ 14.24, $P<0.05$. However, the interaction of the effects of the direction of the switch with the third of the experiment was not significant $F(2,6)=1.17$.

\section{Discussion}

The depletion procedures used in this experiment clearly produced modifications in the behavior of the jays. The birds learned to choose the depleting patch almost exclusively early in the session, when the prey density was higher in that patch, and also learned to avoid the depleting patch after the prey density had dropped to zero.

Because of this learning, the jays were very efficient. The average maximum number of prey items available per session was 12 (six in the depleting patch in 12 trials and six in the remaining 24 trials in the uniform, non-depleting patch). At the end of the experiment, the average number of prey items found per session was almost 11 . The rules governing the patch choices of the jays resulted in performance which approached a maximizing of the number of prey obtained per session.

Cues were available which provided perfect information on when to switch away from the depleting patch (either number of trials or number of prey), but these cues apparently were not used by the jays (or at least not used accurately). If the birds in the Poissson condition were using the trial number cue, the function relating choice of non-depleting patch to trial number would have had a steeper gradient for these birds than for the binomial birds: it did not (Figure 2). If the binomial birds were using number of prey as a cue, the function relating patch choice to trial number following the last prey item found would have dropped markedly for these birds: it did not (Figure 3). Since we only tested two birds in each condition, this finding of no difference between the Poisson and binomial conditions is somewhat tentative. But the remarkable consistency among all four jays, regardless of experimental condition, is fairly convincing.
These findings suggest two possibilities. Jays, when faced with a depleting patch, may rely on a general switching rule that is not sensitive to the differences between the two conditions. Alternatively, the conditions used in this experiment may not have permitted the manifestation of rules which the jays are capable of using. For example, we strongly suspect that using either less than six prey or less than 12 trials in the depleting patch could have produced the predicted differences between the binomial and Poisson birds. In other words, if jays cannot count six prey, perhaps they can count up to two or three.

These results cannot be viewed as a definitive rejection of the hypothesis of Iwasa et al. (1981). Future research should focus upon other conditions under which predators might be sensitive to differences in prey distribution. As suggested above, patches which become depleted sooner might provide such conditions, as might patches with higher initial prey densities.

The analysis of the events that preceded switches between patches offers some insight into the rules the jays may actually have been using when switching. These analyses suggest that the rule used depended on the direction of the switch. Switches from the uniform, non-depleting patch to the depleting patch were usually preceded by a trial in which a moth was found, but trials without prey usually preceded switches from the depleting to the uniform patch. It appears that the switches from the depleting to the non-depleting patches may have been due to some sort of "run of bad luck" rule (Krebs et al. 1978) since such switches were usually preceded by one or more trials during which no prey were found.

It is important to realize that the choice strategy which would maximize the number of moths found per session does not require that choices of the depleting patch precede choices of the non-depleting patch. The maximum number of moths could be found as long as the depleting patch was entered just once, and was chosen either exactly 12 times in a row or until exactly six prey were found. However, the data unambiguously demonstrate that all the jays eventually chose the depleting patch at the beginning of the session. This suggests that the jays were using a timediscounting rule such as that discussed by Houston et al. (1982; see also Fantino \& Abarca, in press), in which prey that are available immediately are valued more highly than prey which will be available after some delay. 
It was unfortunate that the jays showed an initial position bias in patch choice and that different events preceded switches in each direction at the start of the experiment However, there can be no doubt that the jays altered their behavior during the course of their exposure to the conditions of the experiment, and did not simply maintain pre-existing behavioral patterns. The initial differences were probably due to the previous experience of the birds, during which the left side had been the depleting patch. The finding which may have been affected most by the pre-existing differences is the difference in switching rules as a function of the direction of the switch. Although this difference increased across the experiment, the increase was not significant. Consequently, the implications of this effect must be interpreted cautiously.

\section{Acknowledgments}

We would like to thank Ted Sargent for providing the Catocala specimens used to make the slides. Deborah Olson, Pamela Real, James N. M. Smith, and an anonymous reviewer for Animal Behaviour provided useful comments on an earlier version of this manuscript. The blue jays were collected and maintained under federal scientific collecting permit PRT 2-737 and Massachusetts permit 745 . This research was supported by NSF grant BNS 81-02335.

\section{References}

Charnov, E. L. 1973. Optimal foraging: some theoretical explorations. Ph.D. thesis, University of Washington, Seattle.

Charnov, E. L. 1976. Optimal foraging: the marginal value theorem. Theor. Pop. Biol., 9, 129-136.

Fantino, E. \& Abarca, N. (in press) Choice, optimal foraging and the delay-reduction hypothesis. Behav. Brain Sci.

Gibb, J. A. 1962, L. Tinbergen's hypothesis of the role of specific search images, Ibis, 104, 106-111.

Houston, A., Kacelnik, A., \& McNamara, J. 1982. Some learning rules for acquiring information. In: Functional Ontogeny (ed. by D. J. McFarland), pp. 140-191. London: Plenum Press.

Iwasa, Y., Higashi, M., \& Yamamura, M. 1981. Prey distribution as a factor determining the choice of optimal foraging strategy. Am. Nat., 117, 710-723.

Kacelnik, A. 1979. Studies of foraging behaviour in great tits (Parus major). D.Phil. thesis, Oxford University.

Krebs, J. R., Kacelnik, A., \& Taylor, P. 1978. Test of optimal sampling by foraging great tits. Nature, Lond., 275, 27-31.

Krebs, J. R., Ryan, J. C., \& Charnov, E. L. 1974. Hunting by expectation or optimal foraging? A study of patch use by chickadees. Anim. Behav., 22, 953-964.

McNair, J. N. 1982. Optimal giving-up times and the marginal value theorem. Am. Nat., 119, 511-529.

Pyke, G. H., Pulliam, H. R., \& Charnov, E. L. 1977. Optimal foraging: A selective review of theory and tests. Q. Rev. Biol., 52, 137-154.

Smith, J. N. M. \& Dawkins, R. 1971. The hunting behaviour of individual great tits in relation to spatial variations in their food density. Anim. Behav., 19, 695-706.

Smith, J. N. M. \& Sweatman, H. P. A. 1974. Food searching behavior of titmice in patchy environments. Ecology, 55, 1216-1232. 